\title{
GPS sinyal gürültü oranı verileri ile kar kalınlığının belirlenmesi
}

\author{
Nursu Tunalıoğlu ${ }^{1 *}$ iD, Ali Hasan Doğan ${ }^{1}$ (D), Utkan Mustafa Durdağ ${ }^{1}$ (D) \\ ${ }^{1}$ Yıldız Teknik Üniversitesi, Davutpaşa Kampüsü, Inşaat Fakültesi, Harita Mühendisliği Bölümü, Esenler, İstanbul.
}

Öz: GPS teknolojisi, tektonik aktivitelerin izlenmesi, deformasyon analizi, hassas nokta konumlama gibi pek çok jeodezik çalışma için hassas veri sağlamaktadır. Bu çalışmalarda kullanılacak doğruluğu yüksek verinin analizi için uydulardan gönderilen sinyallerin çok yolluluk etkisinden arındırılması gerekmektedir. Genel bir tanım olarak, bir uydudan yayılan sinyalin GPS/GNSS alıcisına birden fazla yoldan ulaşmasına çok yolluluk denir. Bu çok yolluluk genellikle alıcının yakın çevresinde bulunan yansıma yüzeylerinden kaynaklanmaktadır. Böylece, uydu sinyalleri, doğrudan ve dolaylı yollarl izleyerek alıcıya ulaşırlar. Hassas nokta konum belirleme vb. jeodezik çalışmalarda, çok yolluluk istenmeyen bir etkidir ve ölçülerden arındırılması gerekir. Ancak, son yıllarda yapılan çalışmalar, GPS enterferometrik yansıma yöntemi ile GPS alıcısı etrafindaki farklı yüzeylerden yanstyarak gelen bu istenmeyen GPS sinyallerinin yansıma yüzeyine ait kar kalınlığı, toprak nem oranı, deniz seviyesi değişimi gibi bilgilerin elde edilmesinde kullanılabileceğini göstermiştir. Bu çalışmada, GPS çok yolluluk verilerinden yararlanarak, kar kalınlığının belirlenmesi amaçlanmıştır. Bu amaçla, Alaska'da bulunan AB33 istasyonuna ait 1 Ocak 2015-31 Aralık 2015 tarihlerini kapsayan 1 ylllk GPS verisi kullanılmıs ve mevsimsel değişimleri de içeren 1 yıllık kar kalınlık değişimleri incelenmiştir.

Anahtar Sözcükler: Sinyal-gürültü oranı (SNR), GPS enterferometrik yansıma, Kar kalınlığı, Sinyal çok yolluluğu

\section{Determination of snow depth by GPS signal to noise ratio}

Abstract: GPS technology provides precise data for many geodetic studies such as monitoring the tectonic activities, deformation analysis, high-precision point positioning. For high-accuracy analysis of the data to be used in these studies, the multipath effect should be eliminated from the GPS signals. As a general definition, a satellite emitted signal arrives at the receiver by more than one path is so called multipath. This multipath is usually caused by reflection surfaces around the receiver. Thus, satellite signals reach the receiver by following direct and indirect paths. In geodetic studies, where precise positioning is required, multipath is an undesirable effect and should be removed from measurements. However, recent studies have shown that these unwanted GPS signals, which are reflected from different surfaces around GPS receiver, can be used to retrieval information of the reflecting surface such as snow depth, soil moisture content, sea level change with GPS interferometric reflectometry technique. In this study, it is aimed to determine snow depth from GPS multipath data. For this purpose, 1-year GPS data of the AB33 located in Alaska station for the period of 1 January 2015-31 December 2015 was used and 1-year snow depth variations including seasonal changes were investigated.

Keywords: Signal to noise ratio (SNR), GPS interferometric reflectometry, Snow depth, Multipath 


\section{Giriş}

Atmosfer, kara yüzeyleri, kar ve buz, okyanuslar ve diğer su kütleleri ile canlıları kapsayan karmaşık ve birbiri ile etkileşimli olan iklim sistemi, sistemin içindeki parametrelerin etkisi veya diş zorlamalara bağlı olarak değişim göstermekte ve bunun bir sonucu olarak da buzullarda ve kar kütlelerinde hacimsel azalma meydana getirmektedir. Özellikle küresel ısınmanın etkisi ile küresel anlamda ekolojik doğal fauna ve flora yapısı bozulmaktadır (URL-1). Bu nedenle, mevsimsel kar kalınlığının belirlenmesi ve izlenmesi, su döngüsü başta olmak üzere yer yüzeyindeki iklim ve hidroloji ile ilgili yürütülen araştırmalarda önemli bir konu olmuştur (Larson \& Nievinski, 2012; Chen, Won \& Akos, 2014; Qian \& Jin, 2016). Kar kalınlığındaki değişimlerin izlenmesi ile karın erime hızı ve dünya üzerinde ne kadarlık bir su kütlesinin donduğu tespit edilebilmektir. Bununla birlikte, kar kalınlığının hassas ve sürekli olarak izlenmesi, iklim modellerinin oluşturulmasında ve su temini yönetiminde kuraklık ve su baskınlarının tahmini ve buna bağlı olarak azaltıcı/önlenebilir tedbirlerin alınmasında gereklidir (Larson \& Nievinski, 2012).

Kar kalınlığının belirlenmesinde kullanılan yer-bazlı geleneksel yöntemler, noktasal veriye dayalı olması ve küçük ölçekli alanları kapsaması gibi sınırlayıcı nedenlere sahip olmakla birlikte pahalı ölçme yöntemlerindendir. Son yıllarda yapılan çalışmalar, GPS teknolojisi kullanılarak daha geniş alanlarda kar örtüsüne ait verilerin elde edilebileceği yönünde gelişmeler sunmuştur. Yapılan bu çalışmalar, GPS istasyonlarında toplanan verilerden GPS enterferometrik reflektometre (GPS-IR) yöntemi kullanılarak istasyon civarında depolanan kar kütle hacminin belirlenebildiğini göstermiştir. GPS-IR yöntemi, GPS antenine gelen sinyallerin güçlerindeki farklılıklar arasındaki ilişkiyi kullanmaktadır. Bu yöntemin en önemli avantajlarından birisi de kar kalınlığının belirlenmesi çalışmalarına yönelik olarak, ölçme ve jeodezik amaçlı tesis edilen sürekli gözlem yapan sabit GPS istasyonlarının etrafında olmak üzere geniş bir mekânsal alanda sürdürülebilir olarak güncel verinin toplanmasına olanak sağlamasıdır (Larson vd., 2009).

Bilindiği gibi, sinyal yansıma etkisi, hassas nokta konum belirleme bilgisi gerektiren GPS uygulamalarında konum belirleme hassasiyetine etki eden baskın hata kaynaklarından birisidir. Hassas nokta konum bilgisi elde edebilmek için, diğer GPS hata kaynakları gibi sinyal çok yolluluğunun da GPS sinyallerinden elimine edilmesi gerekmektedir. Ancak, gözlem süresince uydulardan GPS alıcısına doğrudan gelen ve yansıyan sinyaller arasındaki girişimin yoğun olduğu düşük yükseklik açılarında $\left(0^{\circ}-25^{\circ}\right.$ arası) toplanan verilerdeki sinyal gücü değişimleri hesaplanarak, yansıma yüzeyi ile sinyalin kaydedildiği anten faz merkezi arasındaki yükseklik belirlenebilmektedir. GPS anteni, birbirine girişim yapan doğrudan gelen ve yansıyan GPS sinyallerini kaydetmektedir. Hassas nokta konum belirleme için istenmeyen ancak Martin-Neira (1993) tarafından ortaya atılan GPS elektromanyetik dalgalarındaki bu girişimlerin yansıma yüzeylerinin özelliklerinin kestirilmesinde kullanılabilirliği, son yıllarda yeni ve etkin bir araştırma alanının gelişmesini sağlamıştır.

Bu çalışmada, ilk olarak SNR (Signal to Noise Rate - Sinyal Gürültü Oranı) yöntemi ve çok yolluluk arasındaki ilişki açıklanmış, sonrasında SNR yönteminin matematiksel modeli sunulmuştur. Uygulama aşamasında ise Alaska'da bulunan AB33 isimli sürekli gözlem yapan sabit GPS istasyona ait mevsimsel değişimleri içeren 1 yıllık GPS verisi kullanılarak kar kalınlığı belirleme çalışması yapılmıştır. GPS SNR verisi kullanılarak bulunan değerler bu istasyon için yayınlanan günlük periyodik manuel kar kalınlığı ölçümleriyle karşılaştırılmıştır. Elde edilen sonuçlar, bu yöntemin geniş alanlarda kar kalınlığı belirleme çalışmalarında etkin şekilde kullanılabileceğini göstermiştir.

\section{2. Çok Yolluluk Etkisi ve SNR Yöntemi}

GPS sinyallerindeki taşıyıcı fazlarda oluşan çok yolluluk etkisinin antenin yakın çevresindeki yatay düzlem yüzeyden yansıması dikkate alınarak oluşturulmuş olan basitleştirilmiş geometrik modeli Şekil 1'de gösterilmektedir. Buna göre, GPS 
antenine doğrudan ve dolaylı gelen sinyaller, anten faz merkezinde birleşmekte ve aynı alıcıya kaydedilmektedir.

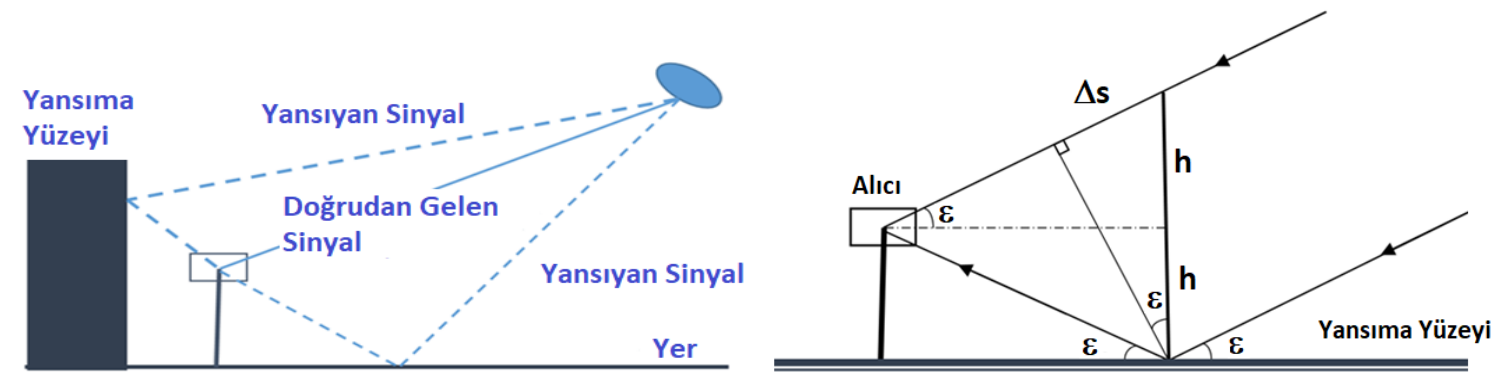

Şekil 1: (sol) Engel/yansıtıcı yüzeyden kaynaklanan çok yolluluk etkisi, (sağ) Yansıma yüzeyinden itibaren düşey yüksekliğe dönüştürülmüş çok yolluluk geometrisi (Hofmann-Wellenhof, Lichtenegger \& Wasle, 2007).

GPS alıcılarında kaydedilen L1 ve L2 taşıyııı frekanslarının yanında, alıcıya gelen sinyallerin şiddetini ifade eden S1 ve S2 gözlemleri de alıcıdan bağımsız veri değişim formatı olan RINEX formatında arşivlenmektedir. Standart RINEX S1/S2 değerleri, taşıyıcı-gürülttü yoğunluk oranı (carrier-to-noise density ratio-C/ $\mathrm{N}_{\circ}$ ) olarak adlandırılan bir büyüklük değerine karşılık gelir. Eşitllik (1)'de verildiği gibi, $\mathrm{C} / \mathrm{N}_{\mathrm{o}}$; sinyal gücünün gürültü gücü spektral yoğunluğuna oranıdır.

$C / N_{o}=\frac{\text { Sinyal Gücü }}{\text { Gürültü Gücü Spektral Yoğunluğu }}$

GPS verilerinden kar kalınlığının belirlenmesi çalışmalarında, SNR gözlemlerinden yararlanılmaktadır. Sinyal gücünün ölçüdeki gürülttüye oranından hesaplanan SNR, genellikle sinyal kalitesi ve klasik GPS ölçülerindeki gürültü özelliklerinin belirlenmesinde kullanılmaktadır (Qian \& Jin, 2016; Tabibi, Geremia-Nievinski,\& van Dam, 2017). Başka bir ifade ile SNR, Eşitlik (2)'de verildiği gibi, C/No ile gürültü bant genişliği (B) üzerinden ilişkilidir.

$S N R=\frac{C / N_{O}}{B}$

Burada, SNR logaritmik ölçekte desibel biriminde iken, lineer ölçekte watt veya volt (volts/volt $=\sqrt{\text { watts/watt) }}$ birimindedir. Genel olarak yapılan çalışmalarda sadeleştirme için $\mathrm{B}=1-\mathrm{Hz}$ bant genişliği alınmış ve lineer ölçeğe dönüştürülmüş (volt) S1/S2 gözlemleri SNR değeri olarak kabul edilmiştir (Larson \& Nievinski, 2012).

Çok yolluluk etkisinin olduğu durumlarda, SNR değerleri, yaklaşık 35 dB'den başlamak üzere 52 dB’e kadar düzgün bir şekilde yükselir. $\mathrm{Bu}$ artış trendi, ilk olarak doğrudan gelen sinyalden ikinci olarak da dolaylı gelen sinyalden kaynaklanmaktadır. Alıcıya gelen sinyallerin gürültü sinyal oranı ile olan ilişkisi ya da bir başka deyişle sinyal gücünde (SNR) yarattı̆̆ı değişim aşağıda verilen eşitlikle ifade edilebilir (Larson vd., 2008; Larson \& Nievinski, 2012; Nievinski \& Larson, 2014);

$S N R^{2} \approx A_{c}^{2}=A_{d}^{2}+A_{m}^{2}+2 A_{d} A_{m} \cos \psi$

Burada; $A_{c}$ girişim yapan sinyalin genliğini, $A_{d}$ doğrudan gelen sinyalin genliğini; $A_{m}$ yansıyan sinyalin genliğini ve $\psi$ bu iki sinyal arasındaki faz farkını göstermektedir (Şekil 2). Bu iki sinyal arasındaki girişim, uydu yükseklik açısı ile doğrudan ilişkilidir. Buna göre, uydu yükseklik açısı arttığında, SNR verilerinde meydana gelen çok yolluluk etkisi azalmaktadır. GPS uydusu geçerken yansıma geometrisi ve $\psi$ değişimi, SNR büyüklüklerinde titreşimler meydana getirir (Larson vd., 2008). 


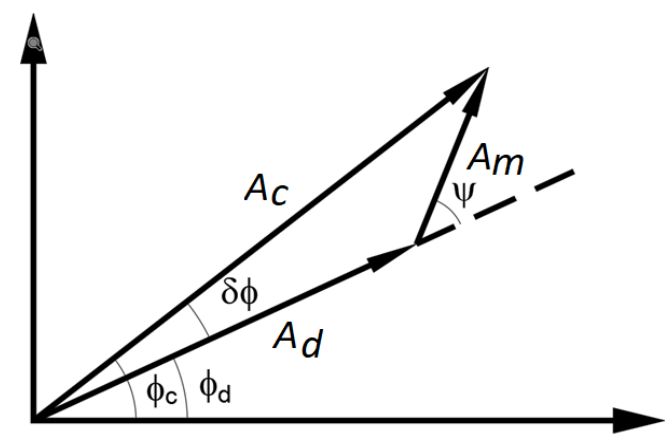

Şekil 2: Taşıyıcı fazda oluşan çok yolluluk etkisi.

Bununla birlikte, çok yolluluk etkisi doğrudan gelen ve yansıyarak gelen GPS sinyalleri arasında taşıyıcı dalga faz kayıklığına $(\delta \phi)$ neden olmaktadır (Şekil 2). $A_{m}$ yansıyan sinyal genliği ile $A_{d}$ doğrudan gelen sinyal genliği arasında, $R f$ yansıma katsayısı olmak üzere $A_{m}=R f A_{d}$ ilişkisi yazııırsa, bu faz kayıklığı aşağıda verilen eşitlikle ifade edilebilir;

$\tan (\delta \phi)=\frac{R f \sin \psi}{1+R f \cos \psi}$

GPS anteninin ve yansıma yüzeyinin hareketsiz olduğu durağan bir ortamda, çok yolluluk fazı, GPS uydusunun hareketine bağlı olarak değişecektir. Bu hareket, faz farkının sinüs (Sin) veya kosinüs (Cos) değerine göre baskın olan SNR verilerinde, çok yolluluk faz hatasında ve çok yolluluk kod (pseudorange) hatasında titreşime neden olmaktadır. Bununla beraber iki sinyal arasındaki faz kayıklığı;

$\psi=\frac{2 \pi}{\lambda} \Delta s$

eşitliği şeklinde yazılabilir. Burada, $\lambda$ GPS taşıyıcı dalga boyu frekansını, $\Delta s$ doğrudan gelen ve yansıyan yüzey arasında yansımadan kaynaklı oluşan ilave yolu ifade eder. Şekil 1 (sağ) dikkate alınırsa bu ilave yol;

$\Delta s=2 h \sin \varepsilon$

olarak yazılabilir.

Eşitlik (5), Eşitlik (6)'da dikkate alınarak yeniden yazılırsa;

$\psi=\frac{4 \pi h}{\lambda} \sin \varepsilon$

elde edilir.

Zamana bağlı değişen faz farkının yükseklik açısına $(\varepsilon)$ göre h mesafesinden yansıyan bir yüzey için, çok yolluluk titreşim frekansi;

$f=\frac{d \psi}{d t}=\frac{4 \pi h}{\lambda} \cos \varepsilon \frac{d \varepsilon}{d t}$

olarak elde edilir (Hofmann-Wellenhof vd., 2008; Bilich, Larson \& Axelrad, 2008; Larson vd., 2008).

Çok yolluluk frekans, faz ve genlik modülasyonları; yansıma yüzeyinin pürüzlülüğü, geometrisi ve bileşeni gibi pek çok 
faktörden kaynaklanmaktadır. Burada, SNR içinde bulunan doğrudan trendlerin etkisi $\left(A_{d}\right.$ ve $\left.A_{m}\right)$ elimine edilirse, çok yolluluk titreşim sinyalleri kalacaktır. SNR'deki doğrudan trendi bulmak için düşük dereceli polinom tüm veriye uygulanarak, SNR trend verileri veri setinden çıkarılır (Larson \& Small, 2016). Çok yolluluk modülasyon frekansı yükseklik açısının sinüsü için sabittir. Yükseklik açısının sinüs değeri bağımsız değişken olarak kullanılırsa, çok yolluluk titreşim frekansı, yansıma yüzeyi ile anten faz merkezi arasındaki düşey mesafenin $(h)$ sabit bir fonksiyonu haline gelir. Böylece, SNR sinyalleri sinüzoidal olarak modellenebilmektedir (Larson vd., 2008):

$$
S N R=A \cos \left(4 \pi h \lambda^{-1} \sin \varepsilon+\psi\right)
$$

Burada, $A$ genliği, $h$ anten faz merkezi ile yansıma yüzeyi arasındaki düşey mesafeyi, $\lambda$ GPS taşıyıcı dalga boyu frekansını, $\varepsilon$ uydu yükseklik açısını göstermektedir. Daha önce de ifade edildiği gibi Eşitlik (9), trendlerin giderildiği (detrend) SNR sinyallerinin modellenmesi için kullanılmaktadır. Böylece, çok yolluluk modülasyon frekansı ile $h$ arasındaki ilişki Eşitlik (10) ile doğrudan elde edilir:

$h=\frac{1}{2} \lambda f$

Burada, $f$ dominant modülasyon frekansı, En Küçük Kareler (EKK) kestirimi ya da Lomb Scargle Periodogramı (LSP) kullanılarak elde edilebilir. Modülasyon frekansı bulunduktan sonra, alıcıda kaydedilen GPS sinyalinin taşıyıcı dalga boyu kullanılarak $h$ değeri hesaplanır. Sonuç olarak, kar kalınlığı, yerden anten faz merkezine olan düşey mesafenin kar tabakasından anten faz merkezine olan düşey mesafeden farkı olarak hesaplanmaktadır.

\section{Uygulama: Kar Kalınlığının Belirlenmesi}

Bu çalışmada, test verisi olarak Amerika Birleşik Devletleri Alaska Eyaleti'nde EarthScope-PBO (The Plate Boundary Observatory) ağına ait sabit bir GPS istasyonu seçilmiştir. Seçilen AB33 isimli bu istasyonun enlem, boylam ve yükseklik değerleri (WGS84) sırasıyla 67.25101 ${ }^{\circ},-150.17254^{\circ}$ ve 335 m’dir. İstasyonda kullanılan GPS alıcısı modeli Trimble NETRS ve anten modeli TRM29659.00'dır. Şekil 3, istasyona ait konum görüntü bilgilerini göstermektedir.

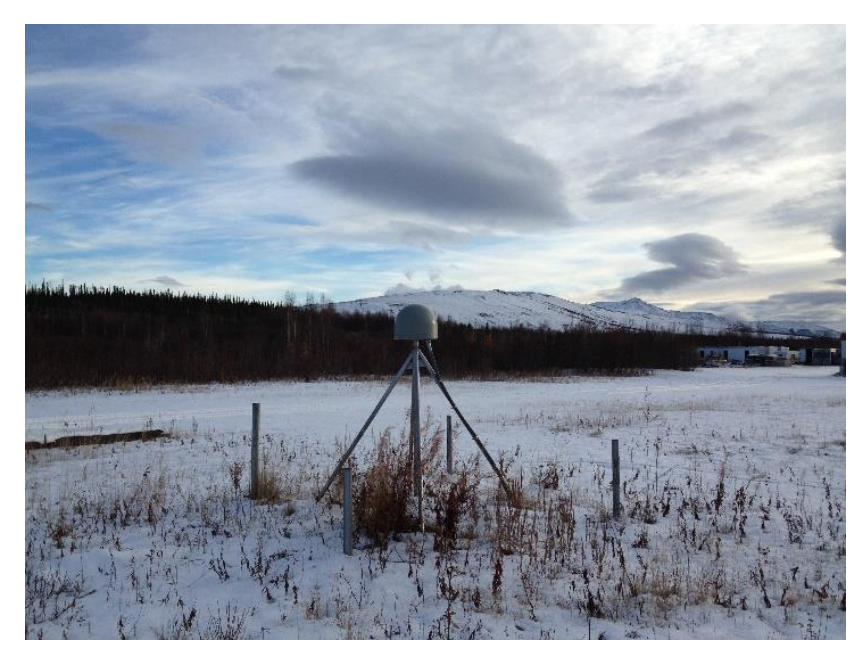

(a)

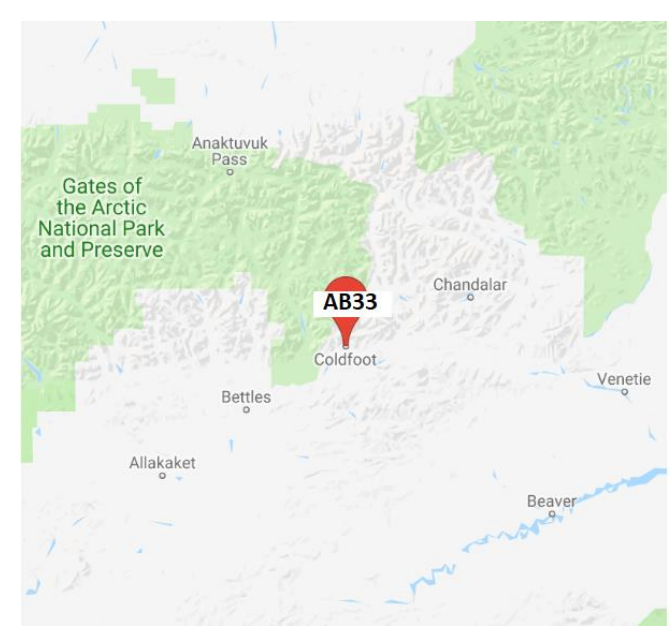

(b)

Şekil 3: (a) AB33 sabit GPS istasyonunun görüntüsü-güney doğrultusu (URL-2). (b) AB33 istasyonunun konumu 
Sürekli gözlem yapan AB33 istasyonuna ait GPS verisinin 2015 yılına ait 1 y1llık bölümü Scripps Orbit and Permanent Array Center (SOPAC) arşivinden temin edilmiştir. İlgili bu GPS verisi için veri kayıt aralı̆̆ı 15 sn'dir. İstasyondaki alıcı tarafından kaydedilen tüm GPS uyduları dikkate alınarak, her bir uydu için çok yolluluk etkisinin görülebileceği düşük yükseklik açısı değer aralığı $\left(5^{\circ}-25^{\circ}\right)$ belirlenmiştir. Bununla birlikte, yeterli sayıda veriyi içeren izlere ait GPS uydularının analizlere katılabilmesi için, günlük veri setleri içinde minimum ve maksimum yükseklik açıları arasındaki farkın $15^{\circ}$ 'den büyük olması koşulu uygulanmıştır. Şekil 4, belirlenen bu koşula uygun olan ve olmayan SNR değerleri için bir örnek sunmaktadır. Ayrıca, her bir uydu izi değerlendirme aşamasına geçmeden önce yükselen ve alçalan izler olarak gruplandırılarak azimut açısına göre yönlerine ayrılmıştır.
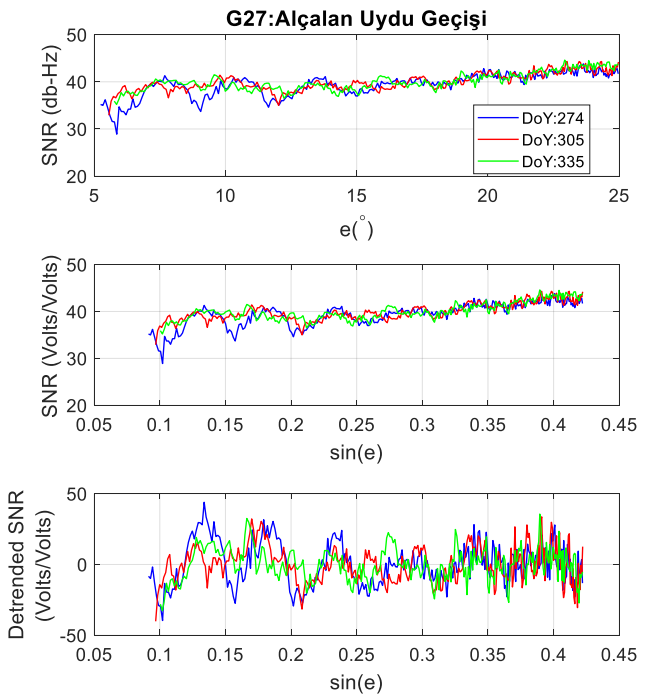

(a)

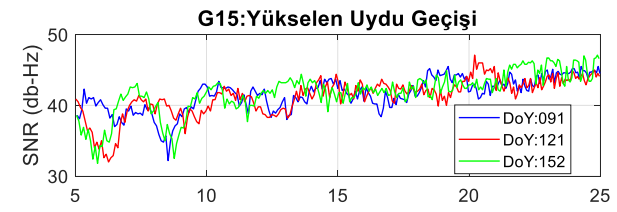

e( )
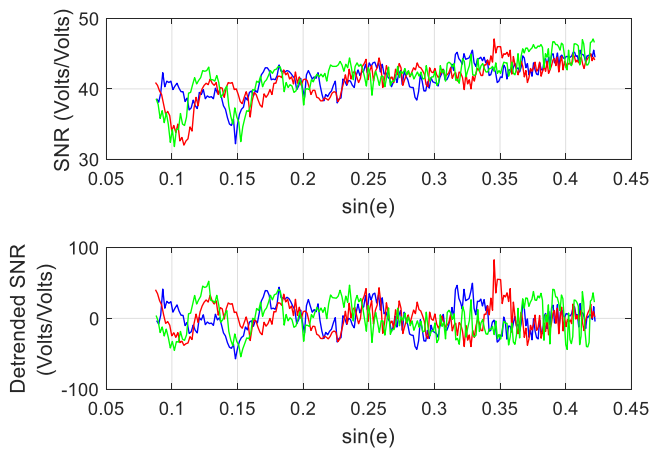

(b)

Şekil 4: AB33 istasyonuna ait gözlenen verilerde yükseklik açısına göre SNR değerleri (a) G27 alçalan uydu geçişi (b) G15 yükselen uydu geçişi

Kar kalınlığı belirleme çalışmalarında yansıyan sinyalin gücü dikkate alındığında, sadece güçlü yansıyan sinyaller hesaplanmıştır. Her bir uydu izi için SNR verileri “Lomb Scarge Periodogramı” yöntemi ile değerlendirilerek sadece güçlü yansımaya sahip günlük veriler bir sonraki analizlerde kullanılmak üzere ayrılmıştır. Bu yöntemdeki periodogramda elde edilen güçlü yansıma verisinin ayrılması için maksimum spektral genlik medyan yöntemi kullanılmıştır. Buna göre, maksimum spektral genlik ile arka planda oluşan spektral genlikler arasındaki farkın 4 kattan büyük olma koşulu aranmıştır. Şekil 5 ve Şekil 6, AB33 istasyonu için sırasıyla, G01 ve G02 alçalan uydu izlerinde ve G09 ile G12 yükselen uydu izlerinde gözlenen 3 günlük verilerde güçlü-zayıf yansıma genliklerini göstermektedir. Bununla birlikte, günlük uydu verilerinin belirlenmesinde 100 epoğun altında olan uydular da değerlendirmede elimine edilerek yeterli sayıya sahip veri gruplarının oluşturulması sağlanmıştır. 


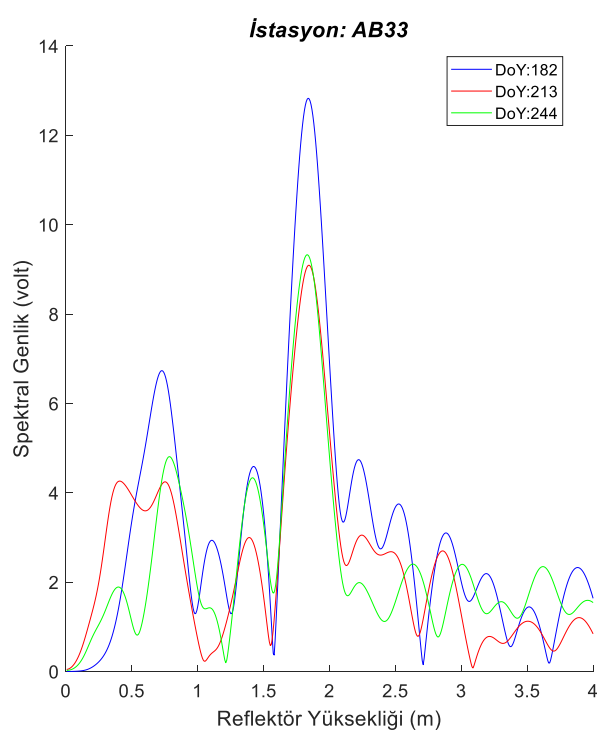

(a)

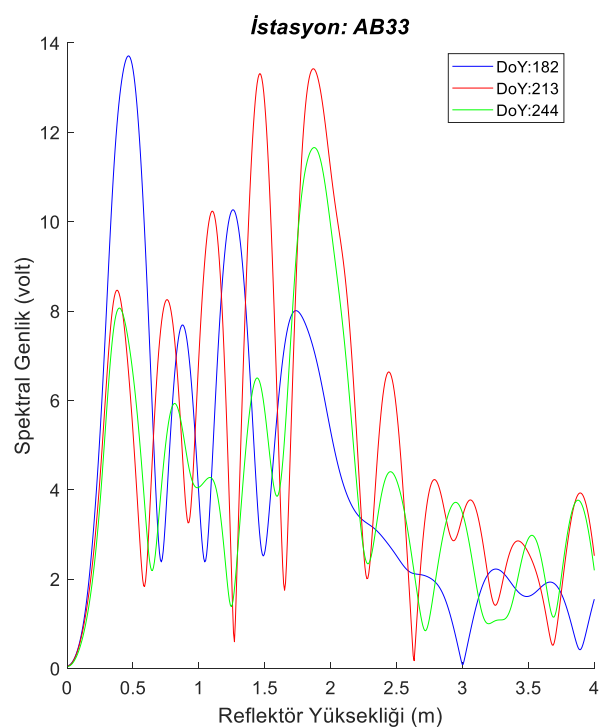

(b)

Şekil 5: AB33 istasyonuna ait üç günlük (mavi çizgi: DoY=182; kırmızı çizgi: DoY=213; yeşil çizgi: DoY=244) detrend SNR verilerinin genlik değişim (a) G01 (alçalan uydu geçişi) için güçlü yansıma (b) G02 (alçalan uydu geçişi) zayıf yansıma grafikleri

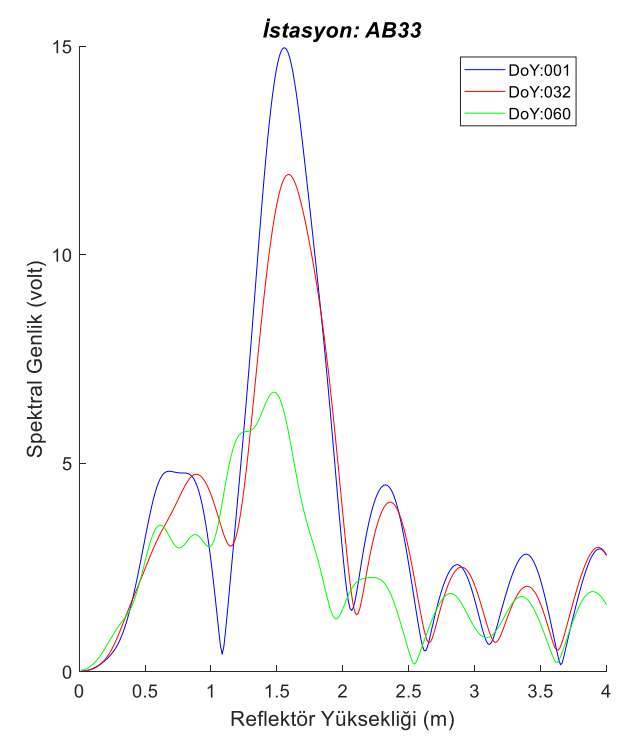

(a)

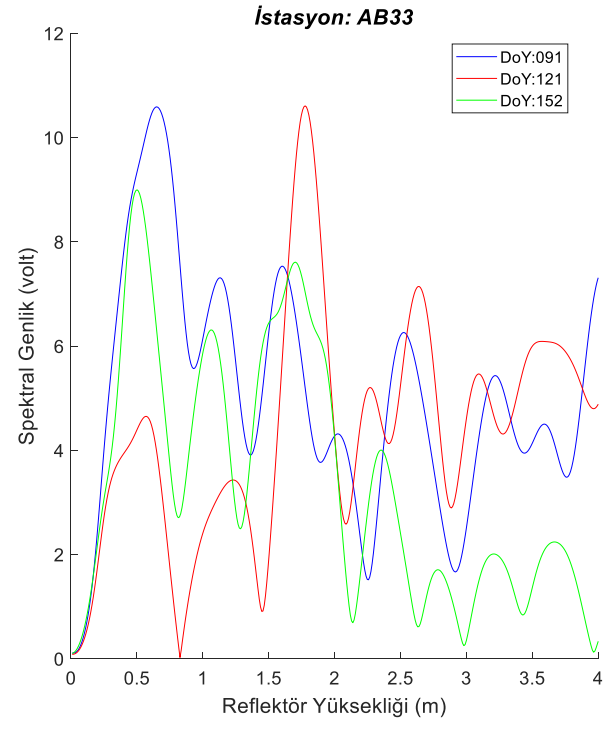

(b)

Şekil 6: AB33 istasyonuna ait üç günlük detrend SNR verilerinin genlik değişim (a) G09 (yükselen uydu geçişi) için güçlü yansıma (b) G12 (yükselen uydu geçişi) zayıf yansıma grafikleri

Çalışmada, yaz dönemi verisi (GPS DoY: 182-196) kar örtüsünün olmadığı durum olarak alınarak ortalama anten yüksekliğinin kestiriminde kullanılmıştır. Bölgeye ait arazide alınan kar kalınlığı doğrulama işlemi, Snowpack Telemetry (SNOTEL) ağına ait Coldfoot (enlem/boylam/yükseklik (WGS84) (d/d/m:67.25/-150.18/317)) gözlem istasyonundan yayınlanan veriler ile yapılmıştır. Şekil 7'de AB33 istasyonuna ait 2015 yılına ait 1 yıllık GPS SNR verileri ile elde edilen kar kalınlığı değişimi görülmektedir. Doğrulama verileri ile yapılan karşılaştırmada Mart-Nisan 2015 tarihlerini kapsayan aralıkta GPS SNR verilerinin aynı trendi koruduğu ancak araziden alınan değerlerden bir miktar düşüşlerin elde edildiği görülmektedir. Aynı durumun, Kasım-Aralık 2015 tarihlerini kapsayan dönem için de geçerli olduğu görülmektedir. 


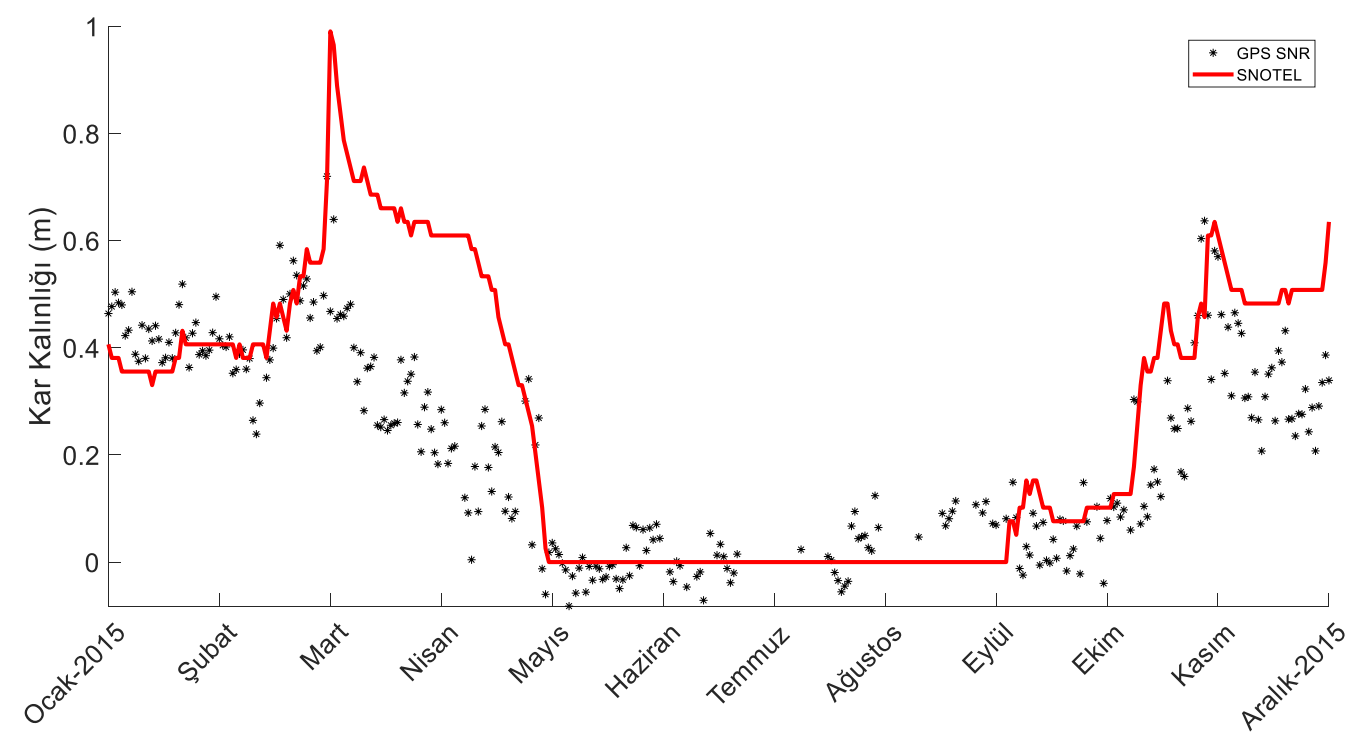

Şekil 7: AB33 istasyonu için L1 frekansı kullanılarak detrend SNR verilerinden elde edilen 1 yıllık kar örtüsü değişim grafiği ve yer doğrulama ölçüleri

Şekil 7'de elde edilen grafik, tüm uyduların birlikte değerlendirilerek ortalaması alınarak hesaplanmıştır. Buna göre, değerlendirmedeki koşulları sağlayan tüm uydu izleri ile düşey yükseklik hesaplanmış ve uydunun azimut açısı dikkate alınmayarak her gün için ortalama değer bulunmuştur.

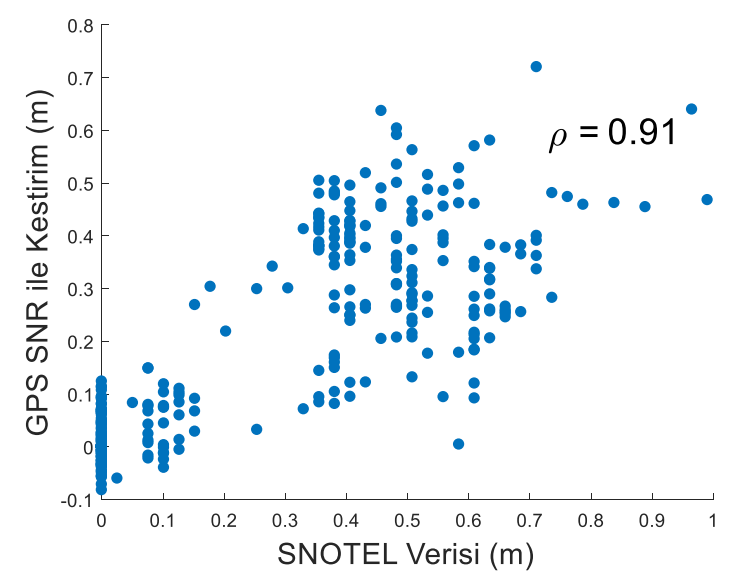

Şekil 8: AB33 istasyonu için GPS SNR verileri ile kestirilen kar kalınlıklarının arazi değerleriyle karşılaştırılması

Şekil 8 AB33 istasyonu için GPS SNR verileri ile kestirilen kar kalınlıklarının arazi ölçümleri sonucunda elde edilen değerlerle karşılaştırmasını göstermektedir. İki veri seti arasındaki korelasyon katsayısı değeri $(\rho) 0.91$ olarak hesaplanmıştır. $\mathrm{Bu}$ durum aralarında yüksek korelasyon olduğunu göstermektedir.

GPS SNR verileri ile kar kalınlığı belirleme çalışmalarına etki eden pek çok faktör bulunmaktadır. Bunlar içerisinde çalışma alanının eğimi ve alana ait bitki örtüsü, elde edilen sonuçların analizinde oldukça önemli faktörlerdir. Bu nedenle ileride yapılacak çalışmalarda, bölgeye ait bu verilerin de değerlendirmeye katılması gerekliliği ortaya çıkmaktadır.

\section{Sonuçlar}

GPS gözlemleri ile hassas nokta konum belirlemede bozucu etkiye sahip olan çok yolluluk etkisi ölçülerde istenmeyen ve elimine edilmesi gereken bir hata kaynağıdır. Son yıllarda yapılan çalışmalar bu hata kaynağının özelliğinin kullanılarak, 
yansıma yüzeyi hakkında bilgi elde edilmesi için kullanılabilirliğini yeni bir araştırma alanı olarak ortaya koymuştur. GPS antenine doğrudan ve yansıyarak gelen GPS sinyalleri aynı alıcıda sinyal girişimi meydana getirmektedir. Girişim yapan bu sinyallerin sinyal enterferometrisi ile analiz edilmesi yansıyan sinyal özelliklerinin belirlenmesinde kullanılmaktadır. $\mathrm{Bu}$ çalışmada, sürekli gözlem yapan GPS istasyonundan elde edilen gözlem verisinde SNR değerleri kullanılarak yansıma yüzeyinin anten faz merkezine olan düşey yüksekliğinin belirlenmesi amaçlanmıştır. Bu amaçla, 2015 yılına ait bir yıllık periyodu kapsayan Alaska'daki AB33 isimli sabit GPS istasyonundan elde edilen gözlemler değerlendirilerek, istasyon civarındaki kar kütlelerinin tespiti yapılmıştır. SNR verileri ile elde edilen kar kalınlıkları, arazide yerinde ölçümle alınan değerlerle karşılaştırılmıştır. Elde edilen sonuçlar, her iki veri seti arasında ilişkinin yüksek korelasyon katsayısı değerine sahip olduğunu göstermektedir. Bununla birlikte, bu kapsamda yapılacak çalışmalarda değerlendirme sürecine etki edebilecek arazi eğimi, bitki örtüsü, yüzey pürüzlülüğü gibi faktörlerin de dikkate alınması farklı sonuçların elde edilmesinde önemli bir kriter olabilir.

Günümüzde küresel ısınmaya bağlı çalışmalar sürdürülebilir doğa ve insan yaşamı açısından büyük önem taşımaktadır. Bu nedenle atmosfer, kara yüzeyleri, kar ve buz, okyanus-deniz suyu değişimi, buzul ve kar hacmi kütlelerinin belirlenmesi küresel anlamda ön plana çıkan bilimsel araştırma konularıdır. GPS çok yolluluk etkisi kaynaklı SNR değerlerinin kullanılarak kar hacminin hesaplanması bu bağlamda efektif çözüm sunan bir teknik olarak ön plana çıkmaktadır.

\section{Kaynaklar}

Bilich, A., Larson, K. M., \& Axelrad, P. (2008). Modeling GPS phase multipath with SNR: Case study from the Salar de Uyuni, Boliva. Journal of Geophysical Research: Solid Earth, 113(B4).

Chen, Q., Won, D., \& Akos, D. M. (2014). Snow depth sensing using the GPS L2C signal with a dipole antenna. EURASIP Journal on Advances in Signal Processing, 2014(1), 106.

Hofmann-Wellenhof, B., Lichtenegger, H., \& Wasle, E. (2007). GNSS-global navigation satellite systems: GPS, GLONASS, Galileo, and more. Springer Science \& Business Media.

Larson, K. M., Small, E. E., Gutmann, E., Bilich, A., Axelrad, P., \& Braun, J. (2008). Using GPS multipath to measure soil moisture fluctuations: initial results. GPS Solutions, 12(3), 173-177.

Larson, K. M., Gutmann, E. D., Zavorotny, V. U., Braun, J. J., Williams, M. W., \& Nievinski, F. G. (2009). Can we measure snow depth with GPS receivers?. Geophysical Research Letters, 36(17).

Larson, K. M., \& Nievinski, F. G. (2013). GPS snow sensing: results from the EarthScope Plate Boundary Observatory. GPS Solutions, 17(1), 41-52.

Larson, K. M., \& Small, E. E. (2016). Estimation of snow depth using L1 GPS signal-to-noise ratio data. IEEE Journal of Selected Topics in Applied Earth Observations and Remote Sensing, 9(10), 4802-4808.

Martin-Neira, M. (1993). A passive reflectometry and interferometry system (PARIS): Application to ocean altimetry. ESA Journal, 17(4), $331-355$.

Nievinski, F. G., \& Larson, K. M. (2014). Inverse modeling of GPS multipath for snow depth estimation-Part I: Formulation and simulations. IEEE Transactions on Geoscience and Remote Sensing, 52(10), 6555-6563.

Qian, X., \& Jin, S. (2016). Estimation of snow depth from GLONASS SNR and phase-based multipath reflectometry. IEEE Journal of Selected Topics in Applied Earth Observations and Remote Sensing, 9(10), 4817-4823.

Tabibi, S., Geremia-Nievinski, F., \& van Dam, T. (2017). Statistical comparison and combination of GPS, GLONASS, and multi-GNSS multipath reflectometry applied to snow depth retrieval. IEEE Transactions on Geoscience and Remote Sensing, 55(7), 3773-3785.

URL-1: T.C. Tarım ve Orman Bakanlığı, Meteoroloji Genel Müdürlüğü, https://www.mgm.gov.tr/iklim/iklim-degisikligi.aspx.

URL-2: https://www.unavco.org/instrumentation/networks/status/pbo/photos/ab33. 